\title{
Correction to: Assessing sleep-wake survival dynamics in relation to sleep quality in a placebo-controlled pharmacological intervention study with people with insomnia and healthy controls
}

\author{
Lieke W. A. Hermans ${ }^{1}$ (D) Marta Regis ${ }^{2} \cdot$ Pedro Fonseca $^{1,3} \cdot$ Sebastiaan Overeem ${ }^{1,4} \cdot$ Tim R. M. Leufkens ${ }^{3}$. \\ Annemiek Vermeeren ${ }^{5}$. Merel M. van Gilst ${ }^{1,4}$
}

Published online: 29 October 2020

(C) Springer-Verlag GmbH Germany, part of Springer Nature 2020

\section{Correction to: Psychopharmacology}

$$
\text { https://doi.org/10.1007/s00213-020-05660-3 }
$$

In the first column of table 2 , it says: 'REM Weibull scale, $1 / \kappa^{\prime}$ ' NREM Weibull scale $1 / K$, and Wake Weibull scale $1 / K$. However, in the published paper, the $K$ is not visible anymore and the text reads ' $1 /$ '. The publisher wish to apologize for this error.

The original article has been corrected.

Publisher's note Springer Nature remains neutral with regard to jurisdictional claims in published maps and institutional affiliations.

The online version of the original article can be found at https://doi.org/ $10.1007 / \mathrm{s} 00213-020-05660-3$

Lieke W. A. Hermans

1.w.a.hermans@tue.nl

1 Department of Electrical Engineering, Eindhoven University of Technology, De Zaale, Eindhoven, The Netherlands

2 Department of Mathematics and Computer Science, Eindhoven University of Technology, De Zaale, Eindhoven, The Netherlands

3 Philips Research, High Tech Campus 34, Eindhoven, The Netherlands

4 Sleep Medicine Center Kempenhaeghe, Sterkselseweg 65, Heeze, The Netherlands

5 Department of Neuropsychology and Psychopharmacology, Faculty of Psychology and Neuroscience, Maastricht University,

Universiteitssingel 40, Maastricht, The Netherlands 